\title{
The Effect of Chloramphenicol on Growth and Mitochondrial Structure of Pythium ultimum
}

\author{
By R. MARCHANT AND D. G. SMITH \\ Department of Botany, University College, Gower Street, \\ London, W.C. I
}

(Accepted for publication I6 August 1967 )

SUMMARY

Chloramphenicol was found to inhibit the growth of Pythium ultimum, showing a maximum dose-response at a concentration of Ioo $\mu \mathrm{g} . / \mathrm{ml}$. Mycelium grown in the presence of chloramphenicol $100 \mu \mathrm{g} . / \mathrm{ml}$., was devoid of the mitochondrial cytochromes $a a_{3}$ and $b$ but contained increased cytoplasmic cytochrome $c$. Mitochondria in thin sections of hyphae grown in the presence of chloramphenicol resembled mitochondria in normal hyphae. In negatively stained preparations of isolated normal mitochondria stalked particles were observed on the cristae. These particles could not be demonstrated in mitochondria from hyphae grown in the presence of chloramphenicol I00 $\mu \mathrm{g} . / \mathrm{ml}$.

\section{INTRODUCTION}

Until recently chloramphenicol was considered to be a fairly specific inhibitor of protein synthesis in prokaryotic organisms (bacteria, blue-green algae), with little or no effect on eukaryotic cells at concentrations which completely inhibit bacterial growth (Vazquez, I966). Several authors have reported that chloramphenicol can uncouple phosphorylation (Hanson, Stoner \& Hodges, 1964) or inhibit protein synthesis and utilization of ATP (Morris, I966a,b) in eukaryotic cells. These effects were, however, only observable at concentrations of chloramphenicol I $\mathrm{mg} . / \mathrm{ml}$. or more, whereas most bacterial systems are inhibited by $2-10 \mu \mathrm{g} . / \mathrm{ml}$. The role of chloramphenicol as a specific inhibitor of protein synthesis in intact eukaryotic cells is therefore in doubt. Several workers (Mager, 1960; Kroon, 1963) have reported that chloramphenicol inhibits amino acid incorporation by intact mitochondria from several sources. However von Ehrenstein \& Lipmann (I96I), So \& Davie (I963) and Bretthauer et al. (1963) showed that chloramphenicol did not inhibit amino acid incorporation by isolated cytoplasmic ribosomes from animal and yeast cells. It would seem therefore that chloramphenicol ought to cause a specific inhibition of mitochondrial protein synthesis in vivo at low concentrations if it were able to penetrate the cells sufficiently well. Huang et al. (I966) reported a seemingly specific inhibition by chloramphenicol of mitochondrial cytochrome synthesis in yeast and have coupled this with observations on the disorganization of the mitochondrial cristae. The strain of Saccharomyces cerevisiae which they used only showed this inhibition at concentrations of chloramphenicol $4 \mathrm{mg}$. $/ \mathrm{ml}$. medium, and as already pointed out this concentration of chloramphenicol acts as a general inhibitor in many organisms. During the screening of a group of fungi for chloramphenicol sensitivity, two were 
found which were inhibited by chloramphenicol at $100 \mu \mathrm{g} . / \mathrm{ml}$. or less. The present report concerns the effect of chloramphenicol on the growth and ultrastructure of one of these organisms, Pythium ultimum.

\section{METHODS}

Organism. The organism used was an isolate of Pythium ultimum Trow (provided by Dr A. P. J. Trinci, Queen Elizabeth College, London); stock cultures were maintained on oatmeal agar (Marchant, Peat \& Banbury, 1967) and grown at $25^{\circ}$.

Growth experiments. The effect of chloramphenicol on the growth of the organism was measured in liquid culture for dry-weight production, or on a solid medium for rate of linear growth. The liquid culture medium used was that of Hendrix \& Lauder (I966) at $\mathrm{pH} \mathrm{7.0} \mathrm{without} \mathrm{added} \mathrm{thiamine.} \mathrm{The} \mathrm{rate} \mathrm{of} \mathrm{linear} \mathrm{growth} \mathrm{of} \mathrm{the} \mathrm{organism} \mathrm{in}$ the presence of chloramphenicol $100 \mu \mathrm{g} . / \mathrm{ml}$. was compared with the control rate on oatmeal agar in $30-\mathrm{cm}$. growth tubes at $25^{\circ}$.

The sensitivity of Pythium ultimum to increasing concentrations of chloramphenicol was ascertained by measuring the dry-weight of duplicate samples grown in stationary liquid culture in $250 \mathrm{ml}$. conical flasks at $25^{\circ}$. The rate of growth, in terms of dry-weight production, in the presence of chloramphenicol $100 \mu \mathrm{g} . / \mathrm{ml}$. was measured on duplicate samples from stationary liquid cultures over a period of seven days.

Measurement of cytochromes. The absorption spectra of the cytochromes were measured in vivo with a Unicam SP800 spectrophotometer. The hyphal material was placed in a cuvette and read against a scattering blank. Cotton-wool was found to give the same result as extracted hyphae as the blank and was therefore used. The extinction of the experimental material was adjusted against a single blank to give a constant extinction. The cytochrome spectra were recorded between 500-650 $\mathrm{m} \mu$ from normal hyphae and from hyphae grown in chloramphenicol $100 \mu \mathrm{g} . / \mathrm{ml}$. for 6 days in liquid culture at $25^{\circ}$. The effect on the cytochrome spectrum was also noted when normally grown hyphae were treated with chloramphenicol $\mathrm{I} 00 \mu \mathrm{g}$. $/ \mathrm{ml}$. for $24 \mathrm{hr}$.

Isolation of mitochondria. The mitochondria were isolated from normal hyphae and hyphae grown in chloramphenicol $100 \mu \mathrm{g} . / \mathrm{ml}$. for 6 days at $25^{\circ}$ by the following method. After harvesting and washing mycelium, the equivalent of $100-300 \mathrm{mg}$. dry wt was blended for $15 \mathrm{sec}$. at $80 \%$ maximum speed in a Vertis blendor in $5 \mathrm{ml}$. isolation medium. The isolation medium comprised $0.65 \mathrm{M}$-mannitol $+0.1 \mathrm{mM}$-EDTA in $20 \mathrm{mM}$-tris buffer ( $\mathrm{pH} \mathrm{6.5)}$. All the extraction and centrifugation procedures were done at $2-4^{\circ}$. The blended material was centrifuged three times at $2000 \mathrm{~g}$ to remove debris and then at $9500 \mathrm{~g}$ to sediment the mitochondria. The mitochondrial pellet was subsequently washed with $2 \mathrm{ml}$. fresh medium and centrifuged down before being used for electron microscopy. The respiratory activity of these isolated mitochondria was not examined.

Electron microscopy. The isolated mitochondria were examined by negative-staining and thin-sectioning techniques. Two negative stains were used, $2 \%$ potassium phosphotungstate $(\mathrm{pH} 7 \cdot 4)$ and $2 \%$ aqueous uranyl acetate. Material from mitochondrial pellets was spread on the surface of drops of negative stain and then picked upon on carbon-formvar coated grids (Parsons, 1963). For sectioning, mitochondria were fixed in $2 \%$ osmium tetroxide which was made iso-osmotic with the isolation medium by the addition of mannitol. The pellet of fixed mitochondria was washed, dehydrated in tert.-butanol mixtures (Johansen, 1940) and embedded in Araldite. Sections were 
stained on the grids with $2 \%$ aqueous uranyl acetate and lead citrate (Reynolds, 1963).

Hyphae of Pythium ultimum grown in the presence and absence of chloramphenicol $100 \mu \mathrm{g}$. $/ \mathrm{ml}$. on oatmeal agar for 4 days at $25^{\circ}$ were fixed in the following way: acrolein $(6 \%)$ in $0 \cdot$ I M-cacodylate buffer $\left(\mathrm{pH}_{7 \cdot 2-7 \cdot 4)}\right.$ for $\mathrm{I} \mathrm{hr}$ at room temperature, followed by thorough washing and post-fixation in I \% buffered osmium tetroxide $(\mathrm{pH} 7 \cdot 2-7 \cdot 4$, Hess, 1966). The material was again dehydrated in tert,-butanol mixtures and embedded in Araldite. All sections were cut with glass knives on an LKB ultratome, and after staining with lead citrate were viewed in a Siemens Elmiskop I electron microscope.

\section{RESULTS}

\section{Growth experiments}

The dose response of Pythium ultimum to chloramphenicol is shown in Fig. I. This response was measured in terms of net dry wt. production after 4 days. The organism showed an increasing response up to a concentration of chloramphenicol $100 \mu \mathrm{g} . / \mathrm{ml}$.,

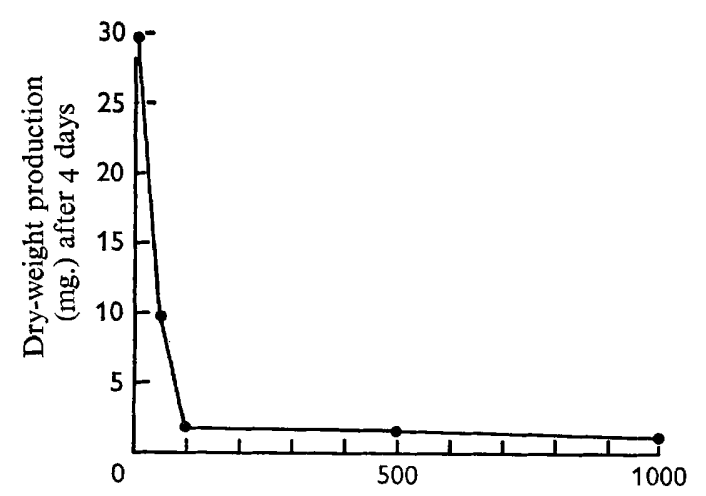

Concentration chloramphenicol $(\mu \mathrm{g} . / \mathrm{ml}$. medium)

Fig. I

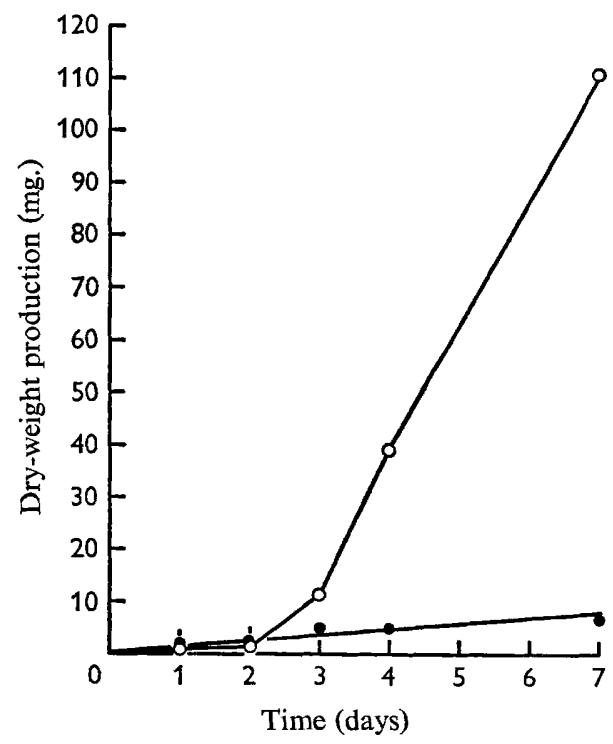

Fig. 2

Fig. I. The effect of concentration of chloramphenicol on the growth of Pythium ultimum, as measured by dry-weight production after 4 days' growth at $25^{\circ}$.

Fig. 2. The dry-weight production of Pythium ultimum grown in the presence and absence of chloramphenicol at $25^{\circ}$. $-\mathrm{O}$, control with no chloramphenicol; $-\bigcirc$, with chloramphenicol $\mathrm{I} 00 \mu \mathrm{g} . / \mathrm{ml}$.

after which further increases in dose produced little more inhibition. Because of this sharp effect at chloramphenicol $100 \mu \mathrm{g}$. $/ \mathrm{ml}$. this concentration was adopted for further studies.

The results of experiments on the effect of chloramphenicol on the rate of growth of the organism are shown in Fig. 2. Duplicate dry wt determinations were done, over a period of 7 days, on mycelium grown in the presence and absence of chloramphenicol. 
The control material, after a lag period, reached an exponential phase of growth and produced about I I0.0 mg. dry wt mycelium in 7 days. The growth of the mycelium in the presence of chloramphenicol $100 \mu \mathrm{g} . / \mathrm{ml}$. remained linear over the period of the experiment and the total production of the organism after 7 days was only $6.3 \mathrm{mg}$ dry wt.

The effect of chloramphenicol on the morphology and growth of Pythium ultimum on a solid medium was investigated in growth tubes; the distance grown along the tube was plotted against time (Fig. 3). The effect of chloramphenicol on the rate of linear growth can be seen to be far less than the effect on dry wt production. The chloramphenicol-treated mycelium on the solid medium, however, had a far lower density of hyphae and less aerial mycelium than the control. These results are comparable with the well known effect obtained when fungi are grown on low carbon source levels. Transfer of chloramphenicol-grown mycelium on to fresh chloramphenicol medium indicated that there was no adaptive mechanism in the hyphae permitting improved growth after prolonged exposure to the drug.
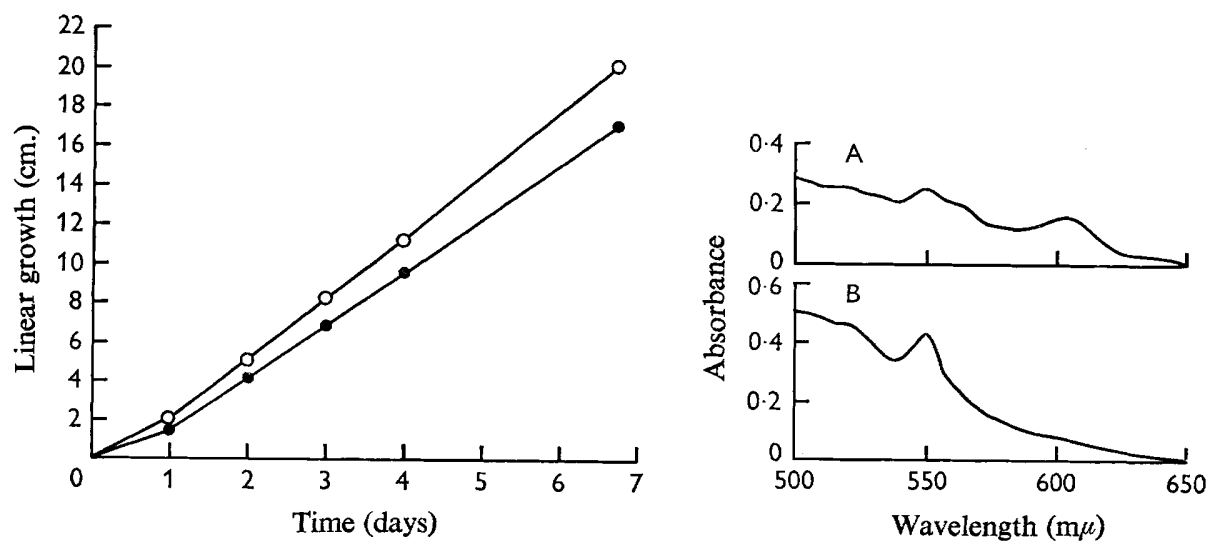

Fig. 3. Linear growth rate of Pythium ultimum across a solid medium at $25^{\circ}$. $0-0$, control with no chloramphenicol; - with chloramphenicol $100 \mu \mathrm{g} . / \mathrm{ml}$.

Fig. 4. Absorption spectra of whole mycelia of Pythium ultimum grown $(a)$ in the absence of chloramphenicol, $(b)$ in the presence of chloramphenicol $100 \mu \mathrm{g} . / \mathrm{ml}$.

\section{Measurement of cytochromes}

The absorption spectra of the cytochromes in normal and chloramphenicol-grown mycelium are shown in Fig. 4. The normal hyphae showed three peaks similar to those in yeast (Huang et al. I966); the peak at $605 \mathrm{~m} \mu$ represents the absorption by cytochrome $a a_{3}$, and those at $562 \mathrm{~m} \mu$ and $550 \mathrm{~m} \mu$ the absorption by cytochromes $b$ and $c$ respectively. The mycelium grown in chloramphenicol showed a complete absence of absorption peaks at 605 and $562 \mathrm{~m} \mu$, indicating inhibition of cytochromes $a a_{3}$ and $b$. There also appeared to be an increase in the cytochrome $c$ concentration in the presence of chloramphenicol. When normally grown mycelium was treated with chloramphenicol for $24 \mathrm{hr}$ there was again a decrease in cytochromes $a a_{3}$ and $b$ and some evidence for the appearance of a peak at $587 \mathrm{~m} \mu$ which Huang et al. (I966) ascribed to cytochrome $a_{1}$, a derivative of cytochrome $a a_{3}$. These results agree closely with those 
of Huang et al. (I966), the only difference being the increase in cytochrome $c$ in Pythium ultimum which was not observed in yeast.

\section{Electron microscopy}

Sections of mature but still active hyphae, from normal mycelium (Pl. I, fig. I) showed few differences from the hyphal apices (Marchant, Peat \& Banbury, 1967). The major difference in organelle structure was in the dense mitochondrial matrix observable in mature regions of the hyphae. Such a difference may be explainable in terms of observations on isolated animal mitochondria (Hackenbrock, 1966), where it was found that freshly isolated mitochondria had a dense contracted matrix but returned to the normal in vivo appearance when allowed to phosphorylate. The structure of hyphae grown in chloramphenicol (Pl. I, fig. 3) shows no difference from the normal hyphae, and even the mitochondrial membranes appear normal, despite the observation of Huang et al. (1966) that chloramphenicol caused the breakdown of the inner mitochondrial membrane in yeast. Sections of isolated mitochondria (Pl. I, fig. 2), although the membranes are not well stained, show that the isolation procedure does not cause a significant alteration in the structure of the mitochondria.

A large proportion of the isolated mitochondria can also be seen to be relatively entire using the negative-staining technique (Pl. 3, fig. 6). When mitochondria isolated from normal hyphae are spread and negatively stained by the method of Parsons (I963) the inner surfaces of the cristae can be seen (Pl. 2, fig. 4) to be covered with the elementary particles reported by Fernández-Morán et al. (1964). When observed more closely (Pl. 2, fig. 5) these elementary particles can be seen to consist of the typical headpiece on a stalk, which is attached to a base-piece in the membrane. We were unable to show this type of elementary particle on the cristae of mitochondria from hyphae grown in chloramphenicol, despite the fact that these mitochondria appeared normal in sections. In an effort to determine whether these elementary particles were in fact absent in the presence of chloramphenicol, mitochondria were subjected to brief (ro sec.) ultra-sonic treatment before being negatively stained. It has already been established (Stasny \& Crane, 1964; Green \& Perdue, 1966) that prolonged severe ultra-sonic treatment is necessary to remove the particles from the membrane. The elementary particles were still visible in normal mitochondria after ultra-sonic treatment, but we were again unable to show them in mitochondria produced in the presence of chloramphenicol.

\section{DISCUSSION}

It now seems fairly certain (Green \& Perdue, 1966) that the electron transport system resides in the base-pieces of the tripartite elementary particles and that some other systems are located in the stalked headpieces (Racker, Chance \& Parsons, 1964). The complete inhibition of competent cytochromes $a a_{3}$ and $b$ by chloramphenicol in the mitochondria is indicated by the absorption spectra obtained. If the disappearance of the stalked particles from the membrane is linked to the absence of the cytochromes it is likely that there has either been a reorganization of the whole membrane structure, absorbing the particles into the main structure, or they have become detached. It is not possible to exclude the possibility that the disappearance of the stalked particles is correlated with some other effect of chloramphenicol in the mitochondria. 
The growth data suggest that a low supply of energy is available for the growth of the organism in the presence of chloramphenicol, and coupled with the structural evidence indicates a specific effect of chloramphenicol on the mitochondria. This is further borne out by the selective inhibition of cytochromes $a a_{3}$ and $b$ and adds further weight to the hypothesis that the protein synthesizing system in the mitochondrion may be analagous to the system in prokaryotic cells. It is interesting to note that there is a low rate of growth which can not be inhibited even by high concentrations of chloramphenicol. Pythium ultimum is an obligate aerobe (Marchant \& Smith, unpublished) and presumably therefore has no complete anaerobic fermentative metabolism. If this is so the residual uninhibited growth may either be supported by reorganized mitochondrial metabolism or by extra-mitochondrial processes.

We wish to thank Dr D. Wilkie, Mr D. Y. Thomas and Mr L. A. Grivell for helpful discussion. One of us (R.M.) acknowledges the support of a Science Research Council studentship.

\section{REFERENCES}

Bretthauer, R. K., Marcus, L., Chaloupka, J., Halvorson, H. O. \& Bock, R. M. (I963). Amino acid incorporation into protein by cell-free extracts of yeast. Biochemistry, N.Y. 2, 1079 .

Ehrenstein, G. vON \& LiPMANN, F. (1961). Experiments on hemoglobin biosynthesis. Proc. natn. Acad. Sci. U.S.A. 47, 94I.

Fernández-Morán, H., Oda, T., Blair, P. V. \& Green, D. E. (I964). A macromolecular repeating unit of mitochondrial structure and function. Correlated electron microscopic and biochemical studies of isolated mitochondria and submitochondrial particles of beef heart muscle. J. Cell Biol. 22, 63.

Green, D. E. \& Perdue, J. F. (I966). Correlation of mitochondrial structure and function. Ann. N.Y. Acad. Sci. r37, 667.

HACKENBROCK, C. R. (I966). Ultrastructural bases for metabolically linked mechanical activity in mitochondria. I. Reversible ultrastructural changes with change in metabolic steady state in isolated liver mitochondria. J. Cell Biol. 30, 269.

Hanson, J. B., Stoner, C. D. \& Hodges, T. K. (I964). Chloramphenicol as an inhibitor of energylinked processes in maize mitochondria. Nature, Lond. 203, 258.

HENDRIX, J. W. \& LAUDER, D. K. (I966). Effects of polyene antibiotics on growth and sterol-induction of oospore formation by Pythium periplocum. J. gen. Microbiol. 44, I 15.

Hess, W. M. (1966). Fixation and staining of fungus hyphae and host plant root tissues for electron microscopy. Stain Technol. 4r, 27.

Huang, M., Biggs, D. R., Clark-Walker, G. D. \& Linnane, A. W. (I966). Chloramphenicol inhibition of the formation of particulate mitochondrial enzymes of Saccharomyces cerevisiae. Biochim. biophys. Acta II4, 434.

Johansen, D. E. (1940). Plant Microtechnique, ist ed. New York: McGraw-Hill.

Kroon, A. M. (1963). Protein synthesis in heart mitochondria I. Amino acid incorporation into the protein of isolated beef-heart mitochondria and fractions derived from them by sonic oscillation. Biochim. biophys. Acta 72, 39I.

MAGER, J. (1960). Chloramphenicol and chlortetracycline inhibition of amino acid incorporation into proteins in a cell-free system from Tetrahymena pyriformis. Biochim. biophys. Acta $3^{8}$, 150.

Marchant, R., Peat, A. \& Banbury, G. H. (1967). The ultrastructural basis of hyphal growth. New Phytol. 66, 623.

MoRrIS, I. (1966a). Some effects of chloramphenicol on the metabolism of Chlorella. I. The effect on protein, polysaccharide and nucleic acid synthesis. Arch. Mikrobiol. 54, I6o.

MORRIS, I. (I966 b). Some effects of chloramphenicol on the metabolism of Chlorella. II. The effect on permeability and on the internal concentration of adenosine triphosphate (ATP). Arch. Mikrobiol. 54, 169.

Parsons, D. F. (1963). Mitochondrial structure: two types of subunits on negatively stained mitochondrial membranes. Science, N.Y. 140, 985 . 


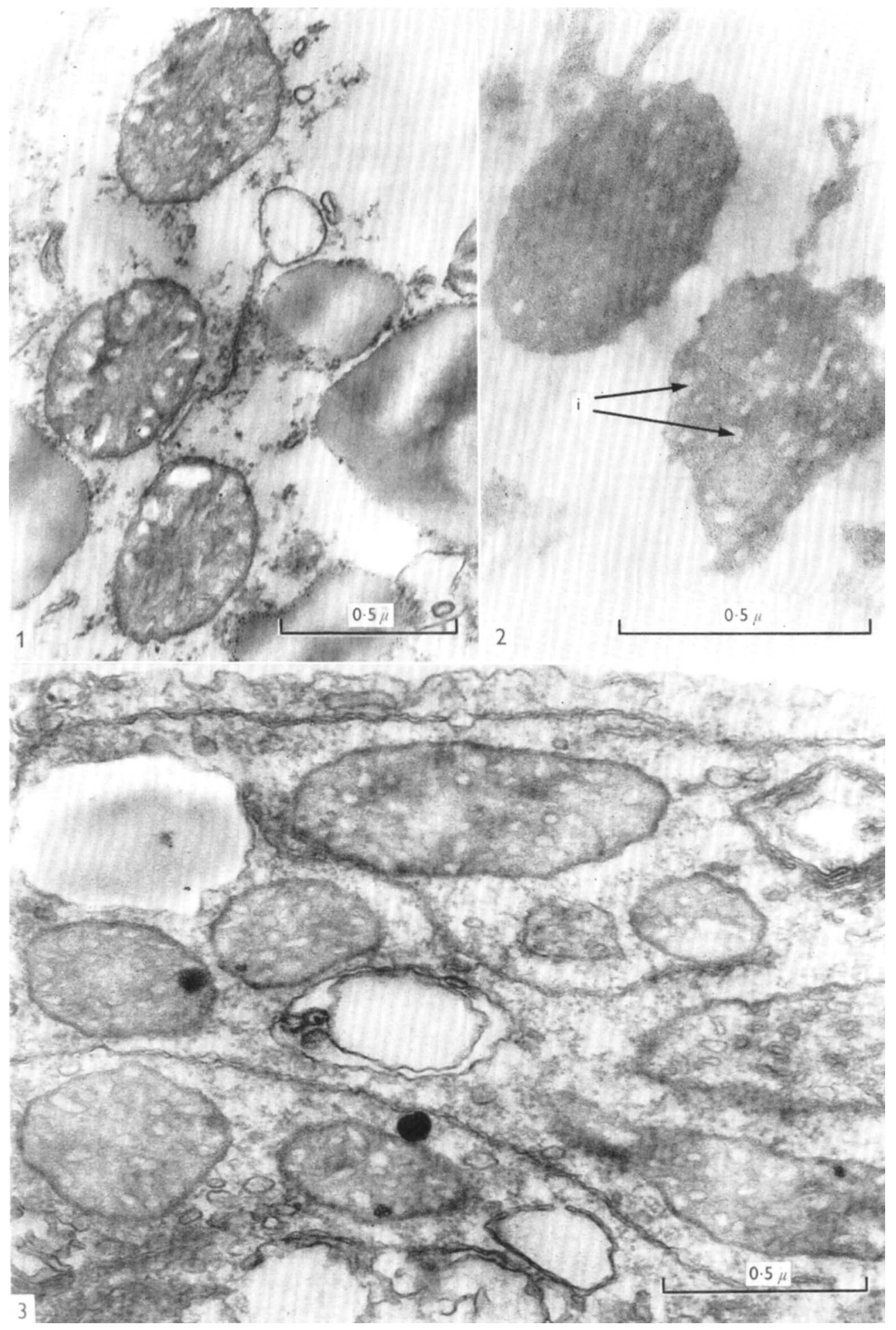


Journal of General Microbiology, Vol. 50, No. 3

Plate 2

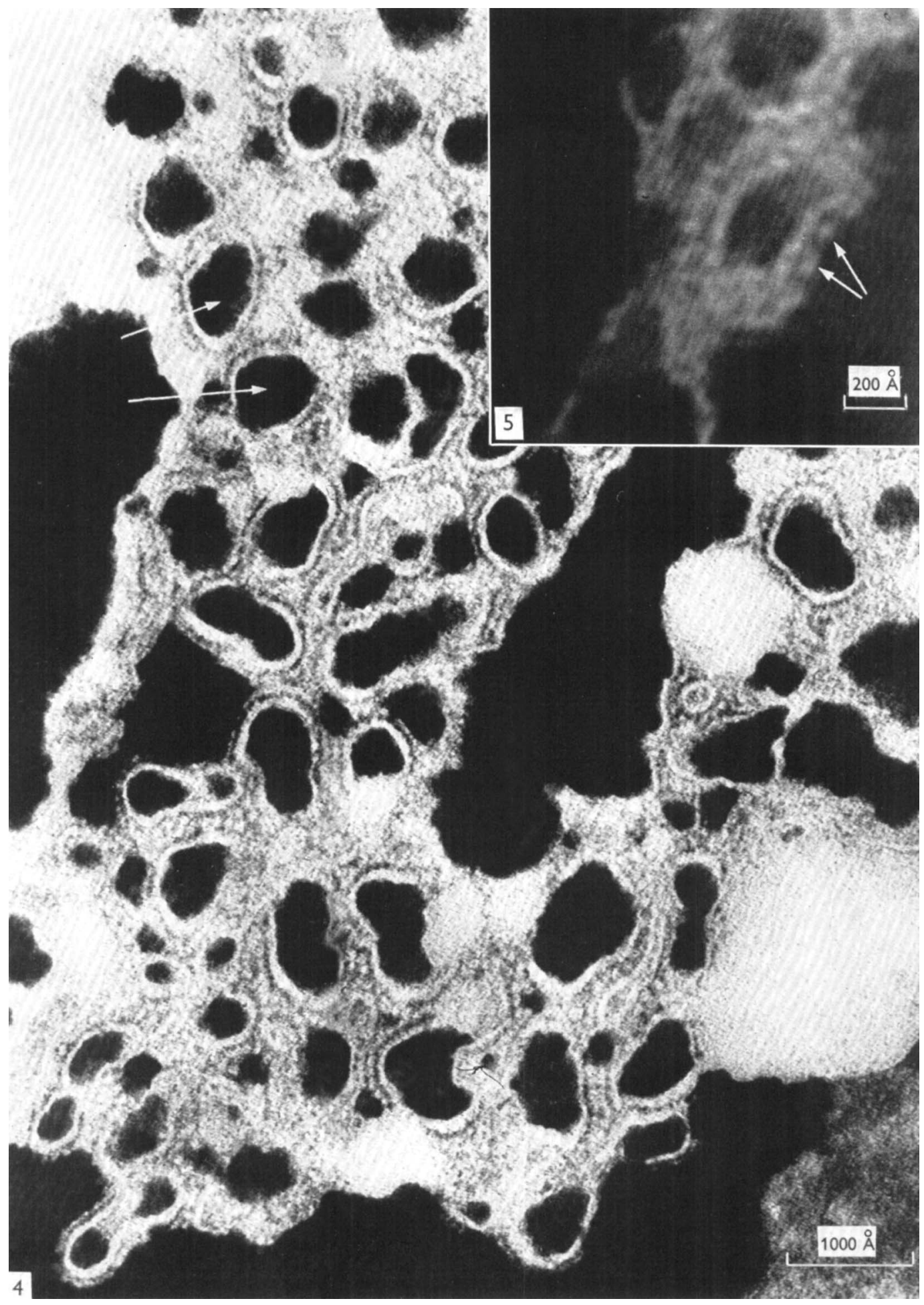




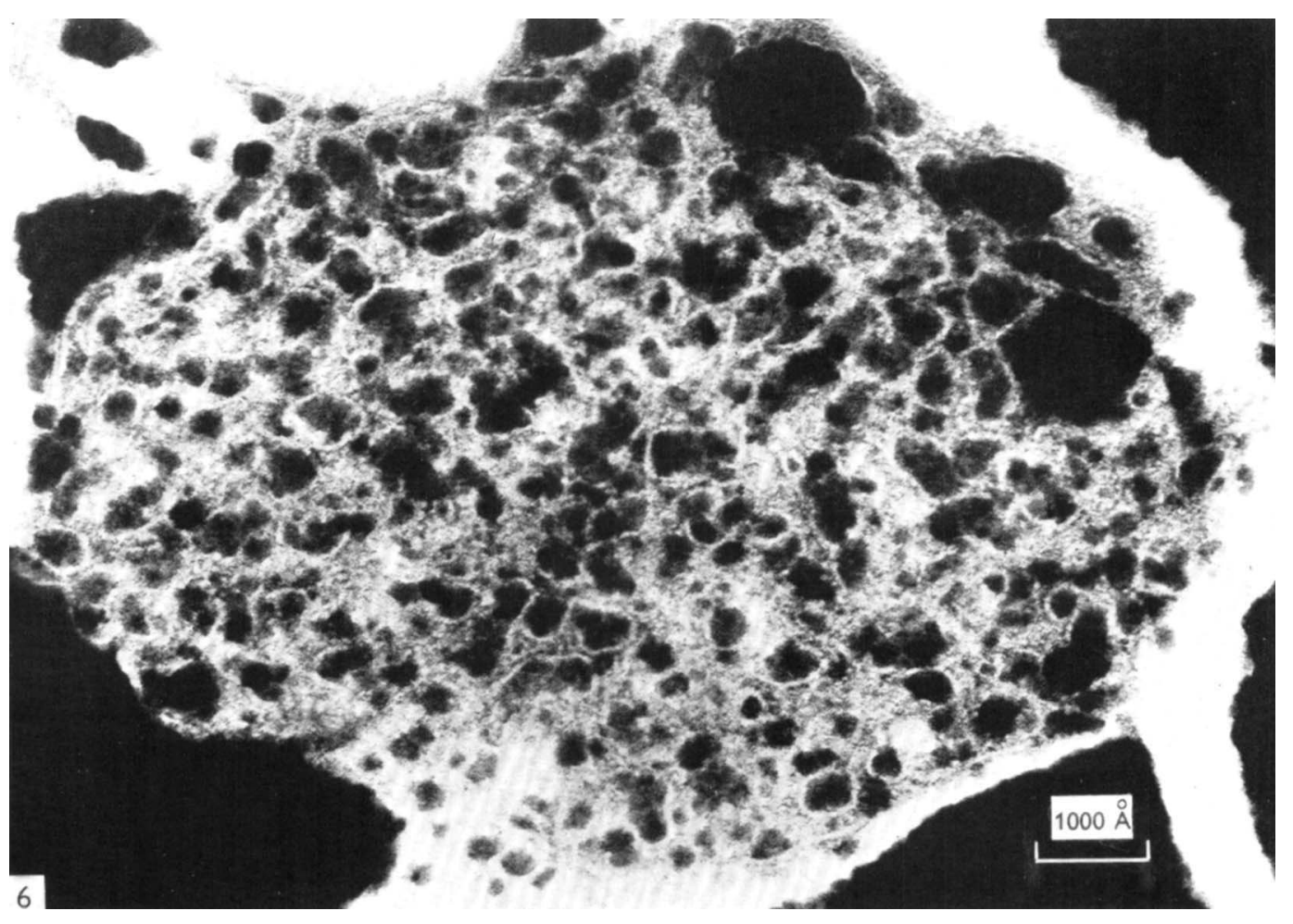


Racker, E., Chance, B. \& Parsons, D. F. (I964). Correlation of structure and function of submitochondrial units in oxidative phosphorylation. Fedn. Proc. 23, $43 \mathrm{I}$.

ReyNolds, E. S. (1963). The use of lead citrate at high $\mathrm{pH}$ as an electron-opaque stain in electron microscopy. J. Cell Biol. 17, 208.

So, A. G. \& DAviE, E. W. (1963). The incorporation of amino acids into protein in a cell-free system from yeast. Biochemistry, N.Y. 2, 132.

Stasny, J. T. \& Crane, F. L. (1964). The effect of sonic oscillation on the structure and function of beef heart mitochondria. J. Cell Biol. 22, 49.

VAzQuez, D. (1966). The mode of action of chloramphenicol and related antibiotics. Symp. Soc. gen. Microbiol. 16, 169 .

\section{EXPLANATION OF PLATES}

Plate I

Fig. I. Thin section of a normal hypha, showing mitochondria with dense matrices. Acrolein fixation $\times 52,000$.

Fig. 2. Thin section of isolated mitochondria from normal hyphae. Note the numerous small intracristal spaces (i). Osmium tetroxide fixation. $\times 75,000$.

Fig. 3. A longitudinal section of a hypha grown in the presence of chloramphenicol $100 \mu \mathrm{g} . / \mathrm{ml}$. There is no apparent difference in mitochondrial structure from those in normal hyphae. Acrolein fixation. $\times 6 \mathrm{r}, 000$.

\section{Plate 2}

Fig. 4. Negatively stained (phosphotungstate) isolated mitochondria from normal hyphae, showing regular distribution of elementary particles and dense intracristal spaces (arrows). $\times$ I 95,000 .

Fig. 5. Higher magnification photograph of stalked particles (arrows) in normal mitochondrion. Negatively stained in phosphotungstate. $\times 480,000$.

\section{Plate 3}

Fig. 6. Negatively stained (phosphotungstate) intact normal mitochondrion. $\times$ I22,000. 